\title{
DESEMPENHO AGRONÔMICO DE GENÓTIPOS DE AMENDOIM NO ESTADO DE GOIÁS
}

\author{
Jair Heuert ${ }^{1}$; Taís de Moraes Falleiro Suassuna ${ }^{1}$, Kennedy Brunno de Brito Martins ${ }^{2}$, Thiago Cândido \\ do Nascimento Ribeiro ${ }^{1}$, Washington da Conceição Gonçalves ${ }^{1}$

\footnotetext{
${ }^{1}$ Embrapa, Santo Antônio de Goiás-GO, jair.heuert@embrapa.br e tais.suassuna@embrapa.br; ${ }^{2}$ Acadêmico de Biologia, Faculdade Araguaia, Goiânia-GO.
}

RESUMO: A cultura do amendoim é importante para a diversificação dos sistemas agrícolas e da economia, trazendo inúmeros benefícios sociais. O desenvolvimento de novas cultivares de amendoim tipo "Runner" adaptadas ao Cerrado é um dos objetivos do programa melhoramento da Embrapa. As principais características selecionadas são: alta produtividade, padrão de grãos "Runner" com alto teor de ácido oleico, tolerânciaàs principais doenças, de ciclo médio e curto. Os ensaios foram conduzidos em Cristianópolis-GO e Santo Antônio de Goiás-GO, empregando o manejo usual para a cultura, porém foi observada elevada severidade de cercosporioses nos dois locais. Foram avaliadas seis linhagens avançadas e três cultivares; os tratamentos foram dispostos em blocos casualizados. Foram avaliadas a severidade de cercosporioses, produtividade e massa de 100 grãos. Houve diferenças significativas em todas variáveis avaliadas. A severidade foi elevada em todos os tratamentos causando desfolha intensa do terço médio. Os genótipos mais produtivos foram 13-413 OL, 13-425 OL, que apresentam também sementes de tamanho regular, 13-374 OL, que apresenta sementes de maior tamanho.

Palavras-chave: Arachis hypogaea L., melhoramento genético.

\section{INTRODUÇÃO}

A cultura do amendoim tem uma grande importância no agronegócio brasileiro, incorporando renda e emprego em toda cadeia produtiva. É um alimento apreciado com alto valor nutritivo, rico em proteína, minerais e vitaminas, que pode ser consumido in natura. É utilizado pela indústria para obtenção de diversos produtos, óleo e farelo de amendoim (LOURENZANI; LOURENZANI, 2006; FREIRE et al., 2005).

Os aumentos de produtividade registrados recentementesão decorrentes da adoção de cultivares de porte rasteiro, tipo "Runner", adaptados à colheita mecânica, com maior potencial produtivo e maior rendimento em todas as etapas do processo de produção (MARTINS; PEREZ, 2006).

O amendoim é produzido principalmente no Estado de São Paulo, porém, outros estados, especialmente na região compreendida pelo Cerrado, vêm se destacando na produção últimos anos, o 
Estado de Goiás é um exemplo. O objetivo desse trabalho foi avaliar genótipos desenvolvidos pelo programa de melhoramento genético de amendoim da Embrapa, no Estado de Goiás.

\section{MATERIAS E MÉTODOS}

O experimento instalado na fazenda Santa Rosa em Cristianópolis-GO, foi semeado no dia 12 de dezembro de 2016. O segundo foi conduzido na área experimental da Embrapa Arroz e Feijão, em Santo Antônio de Goiás-GO, foi semeado em 25 de novembro de 2016. Ambas as áreas foram precedidas por culturas anuaise o manejo da cultura seguiu as recomendações técnicas de controle de plantas daninhas, doenças e pragas, bem como a adubação e gessagem conforme as análises de solo.

Foram avaliadas seis linhagens avançadas da Embrapa 13-368 OL, 13-370 OL, 13-374 OL, 13-413 OL, 13-424 OL e 13-425 OL, e as cultivares Granoleico, IAC 503 e IAC OL 3, como testemunhas. Os tratamentos foram dispostos em blocos casualizados, com nove tratamentos. As parcelas eram formadas por duas linhas de 0,8 e três metros de comprimento no ensaio instalado em Cristianópolis-GO e seis repetições e 0,9 m espaçamento e cinco metros de comprimento no ensaio conduzido em Santo Antônio de Goiás-GO, sendo o estande médio de plantas 17 plantas por metro. A severidade da mancha preta no campo experimental foi avaliada com notas 1-9, conforme a escala diagramática proposta por SUBRAHMANYAM et al.,1982.

Os ensaios foram invertidos aos 133 dias após semeadura, usando arrancador simples e após o período de secagem no campo foram colhidos para determinar a produtividade. A análise de variância foi realizada usando o programa SISVAR 5.6. O teste de médias empregado foi o Scott Knott, a 5\% de probabilidade.

\section{RESULTADOS E DISCUSSÃO}

O experimento de Cristianópolis-GO apresentou elevada produtividade e diferença significativa para todas as variáveis analisadas (Tabela 1). Os menores valores de severidade foram observados nos genótipos 13-368 OL, 13-424 OL, IAC 503 e 13-370 OL. A maior produtividade foi observada na linhagem 13-413 OL (7.372,4 $\left.\mathrm{kg} \mathrm{ha}^{-1}\right)$, seguida pelas linhagens, 13-374 OL e 13-425 OL. A severidade nas linhagens mais produtivas alcançou o terço médio (nota média 7,7). A severidade das cultivares, usadas como testemunhas, foi em média de 8,3 . No entanto, a maior severidade foi observada nas cultivares Granoleico e IAC OL3, que apresentaram desfolha intensa no terço superior das folhas, e também menor produtividade. Provavelmente a desfolha mais severa reduziu a produtividade destas cultivares. Maior tamanho de sementes (massa de 100 grãos) foi observado em IAC 503, 13-374 OL, 13-368 OL e 13-370 OL. 
16 e 17 de agosto de 2018, centro de convenções da FCAV/UNESP - Câmpus de Jaboticabal, SP

Tabela 1 - Avaliação de genótipos de amendoim em Cristianópolis - GO; safra 2016-17.

\begin{tabular}{ccccc}
\hline Genótipo & Severidade & $\begin{array}{c}\text { Produtividade } \\
\text { Kg/ha }^{-1}\end{array}$ & $\begin{array}{c}\text { Peso 100 } \\
\text { Grãos (g) }\end{array}$ & $\begin{array}{c}\text { Produtividade } \\
\text { Sacas/alqueire }\end{array}$ \\
\hline $13-413 \mathrm{OL}$ & $7,8 \mathrm{a}$ & $7.372,4 \mathrm{a}$ & $77,2 \mathrm{~b}$ & 713,6 \\
$13-374 \mathrm{OL}$ & $7,6 \mathrm{a}$ & $6.559,9^{\mathrm{a}}$ & $92,1 \mathrm{a}$ & 635,0 \\
$13-425 \mathrm{OL}$ & $7,5 \mathrm{a}$ & $6.273,4 \mathrm{a}$ & $75,9 \mathrm{~b}$ & 607,3 \\
$13-370 \mathrm{OL}$ & $7,6 \mathrm{a}$ & $5.723,95 \mathrm{~b}$ & $92,1 \mathrm{a}$ & 554,1 \\
IAC 503 & $7,6 \mathrm{a}$ & $5.645,83 \mathrm{~b}$ & $93,2 \mathrm{a}$ & 536,5 \\
$13-424 \mathrm{OL}$ & $7,5 \mathrm{a}$ & $5.281,25 \mathrm{~b}$ & $79,2 \mathrm{~b}$ & 511,2 \\
$13-368$ OL & $7,3 \mathrm{a}$ & $4.710,93 \mathrm{c}$ & $92,7 \mathrm{a}$ & 456,0 \\
Granoleico & $8,4 \mathrm{~b}$ & $3.744,79 \mathrm{c}$ & $77,3 \mathrm{~b}$ & 362,5 \\
IAC OL 3 & $8,7 \mathrm{~b}$ & $3.578,12 \mathrm{c}$ & $75,0 \mathrm{~b}$ & 346,4 \\
\hline Média & 7,8 & $5.432,29$ & 83,88 & - \\
\hline CV (\%) ${ }^{(1)}$ & 3,55 & 15,73 & 2,25 & - \\
\hline F ${ }^{(2)}$ & $11,71^{*}$ & $8,69^{*}$ & $77,92^{*}$ & - \\
\hline
\end{tabular}

Médias seguidas de mesma minúscula na coluna não diferem entre si pelo teste de Scott $\operatorname{Knott}(\mathrm{p} \geq 0,05) \cdot{ }^{(1)} \mathrm{CV}$ : Coeficiente de Variação; ${ }^{(2)}$ *significativo a $1 \%$ de probabilidade pelo teste $\mathrm{F}$.

No ensaio instalado em Santo Antônio de Goiás-GO (Tabela 2), as maiores severidades foram percebidas nas cultivares Granoleico e IAC OL 3, e podem ter influenciado a queda na produtividade de ambas. O desempenho das linhagens 13-413 OL, 13-374 OL e 13-425 OL continuaram superiores aos demais tratamentos para produtividade. Menor severidade foi observada na linhagem 13-374 OL, semelhante a cultivar IAC 503.

Tabela 2-Avaliação de genótipos de amendoim em Santo Antônio de Goiás-GO; safra 2016-17

\begin{tabular}{ccccc}
\hline Genótipo & Severidade & $\begin{array}{c}\text { Produtividade } \\
\text { Kg/ha }\end{array}$ & $\begin{array}{c}\text { Peso 100 } \\
\text { Grãos (g) }\end{array}$ & $\begin{array}{c}\text { Produtividade } \\
\text { Sacas/alqueire }\end{array}$ \\
\hline $13-425 \mathrm{OL}$ & $7,3 \mathrm{~b}$ & $5.745,36 \mathrm{a}$ & $76,33 \mathrm{~b}$ & 556,2 \\
$13-413 \mathrm{OL}$ & $7,5 \mathrm{c}$ & $5.646,29 \mathrm{a}$ & $76,10 \mathrm{~b}$ & 546,6 \\
$13-374 \mathrm{OL}$ & $6,8 \mathrm{a}$ & $4.572,22 \mathrm{~b}$ & $94,03 \mathrm{a}$ & 442,6 \\
$13-370 \mathrm{OL}$ & $7,0 \mathrm{a}$ & $4.314,81 \mathrm{~b}$ & $93,41 \mathrm{a}$ & 417,7 \\
$13-424 \mathrm{OL}$ & $7,6 \mathrm{c}$ & $4.185,18 \mathrm{~b}$ & $78,56 \mathrm{~b}$ & 405,1 \\
$13-368$ OL & $6,6 \mathrm{a}$ & $4.119,44 \mathrm{~b}$ & $92,86 \mathrm{a}$ & 398,8 \\
IAC 503 & $6,8 \mathrm{a}$ & $3.758,88 \mathrm{~b}$ & $90,11 \mathrm{a}$ & 363,9 \\
IAC OL 3 & $8,2 \mathrm{~d}$ & $3.709,25 \mathrm{~b}$ & $77,06 \mathrm{~b}$ & 359,1 \\
Granoleico & $8,1 \mathrm{~d}$ & $3.684,25 \mathrm{~b}$ & $80,25 \mathrm{~b}$ & 356,6 \\
\hline Média & 7,3 & 4415,08 & 84,31 & - \\
\hline CV (\%) & 2,83 & 17,21 & 1,71 & - \\
\hline F ${ }^{(2)}$ & $47,50^{*}$ & $6,39^{*}$ & $186,86^{*}$ & - \\
\hline
\end{tabular}

Médias seguidas de mesma minúscula na coluna não diferem entre si pelo teste de Scott $\mathrm{Knott}(\mathrm{p} \geq 0,05) \cdot{ }^{(1)} \mathrm{CV}$ : Coeficiente de Variação; ${ }^{(2) *}$ significativo a $1 \%$ de probabilidade pelo teste $\mathrm{F}$. 


\section{CONCLUSÃO}

As maiores produtividades foram observadas nas linhagens 13-413 OL, 13-374 OL e 13-425 OL, desenvolvidas pela Embrapa.

Menores produtividades foram observadas em genótipos com desfolha mais intensa, reforçando a importância da obtenção de genótipos com resistência às doenças foliares para o estado de Goiás.

Foram identificados genótipos altamente produtivos e com sementes de maior tamanho, importante para mercados específicos.

Avaliações de genótipos em outros estados serão realizadas visando identificar materiais com adaptabilidade e estabilidade para a região do Cerrado.

\section{AGRADECIMENTOS}

Os autores agradecem ao produtor rural Rafael de Matos Rodrigues da Fazenda Santa Rosa pela disponibilidade da área e condução do experimento em Cristianópolis-GO.

\section{REFERENCIAS BIBLIOGRAFICAS}

FREIRE, R.M.M.; NIRAIN, N.; SANTOS, R.C. Aspectos nutricionais de amendoim e seus derivados. In: SANTOS, R:C. (Ed.). O agronegócio do amendoim no Brasil. Campina Grande: Embrapa Algodão, 2005. p. 389-420.

LOURENZANI, W.L.; LOURENZANI, A.E.B.S. Potencialidades do agronegócio brasileiro de amendoim. In: CONGRESSO DA SOCIEDADE BRASILEIRA DE ECONOMIA E SOCIOLOGIA RURAL, 44., 2006, Fortaleza, Ceará, Brasil. Anais... Fortaleza: Sober, 2006. Acessado em 31/05/2018 MARTINS, R.; PEREZ, L. H. Amendoim: inovação tecnológica e substituição de importações. Informações Econômicas, São Paulo, v. 36, n. 12, p. 7-19, dez. 2006.

SUBRAHMANYAM, P.; MCDONALD, D.; GIBBONS, R. W.; NIGAM, S. N.; NEVILL, D.J. Resistance to rust and late leaf spot diseases in some genotypes of Arachishypogaea. Peanut Science, v.9, p.9-14, 1982. 